American Journal of Applied Sciences 6 (1): 109-113, 2009

ISSN 1546-9239

(C) 2009 Science Publications

\title{
Impedance Method Application for Multi-Layer Structure Testing
}

\author{
Monzer Moh`D Krishan \\ Ma'an University College, Al-Balqa Applied University, Jordan
}

\begin{abstract}
Multi-layer materials and structures are widely used in the modern aircraft industry. The main defect of these structures is delamination. The most appropriate method for detection of such kind flaws is the impedance testing method. This research is devoted to the features of the impedance method for multi-layer panel testing. The theoretical and experimental investigations of mechanical impedance are presented for honeycomb panels. The theoretical investigation provided the analytic expression, which enabled us to determine object parameters such as honeycomb density and thickness, covering thickness and cylindrical rigidity on a test result. The assembly of a combined probe was proposed for experimental investigations of mechanical impedance. An amplitude of the output signal of this probe is depended on the testing object mechanical impedance and flexibility of contact area. Numerical simulation results demonstrate the influence of the object parameters on the effectiveness of the defect detection in honeycomb structure.
\end{abstract}

Key words: Multilayer structure testing, impedance method, aircraft industry, modeling and simulation, honeycomb structure

\section{INTRODUCTION}

Honeycomb structures are widely used in aerospace industry. The fuselage and wings of some aeroplanes consist of multi-layer structure such as honeycomb one. These materials have high toughness and little specific weight. Various types of defects can appear during operation period of time in honeycomb structures. The most common defects of honeycomb structures are delamination of honeycombs from coating and contortion of walls. Presence of such kind of defects has unfavourable influence on any device with mechanical properties. So, the task of finding defects in honeycomb structures is very important.

Acoustical methods of NDE are also used for multi-layer structure testing. The most sensitive method for little defect detection is impedance method ${ }^{[1]}$. The elastic vibrations of low frequency is the base of this method. Impedance method is used for glued junction detection and also exfoliation defect disclose ${ }^{[2]}$. Impedance method is universal and suitable for use.

In general, the honeycomb structure impedance can be expressed as ${ }^{[3]}$ :

$$
Z=\frac{\dot{\mathrm{F}}}{\dot{\mathrm{V}}}=\mathrm{R}_{\mathrm{H}}+\mathrm{j} X_{\mathrm{H}}=|\mathrm{Z}| \mathrm{e}^{\mathrm{j} \varphi}
$$

Where:

$\mathrm{Z}=$ The mechanical impedance of structure
$\mathrm{F}=$ Complex amplitude of applied force

$\mathrm{v}=$ Vibrating velocity in the applied force point

$\mathrm{R}_{\mathrm{H}}, \mathrm{X}_{\mathrm{H}}=$ Active and reactive components of the impedance and $\varphi=\operatorname{arctg}\left(X_{H} / R_{H}\right)$

Mechanical impedance of multi-layer structure in the area of applied force is defined by the all components of this structure connected in the common mechanical system. This system vibrates as a single whole when all layers band each other and the module $|\mathrm{Z}|$ has maximum value. If there is a defect in the place of layers joint, rigidity of this place will be less then flaw-free one. Therefore, the module $|Z|$ of a defect place will be less then flaw-free one and $|Z|$ rotates through some angle. Changing $|\mathrm{Z}|$ leads to changing of a transducer acoustical channel ${ }^{[3]}$ :

$$
\dot{\mathrm{P}}=\frac{\dot{\mathrm{U}}_{\mathrm{II}}}{\dot{\mathrm{U}}_{\mathrm{B}}}=\mathrm{Pe}^{\mathrm{j} \varphi}
$$

where, $\mathrm{U}_{\Pi}, \mathrm{U}_{\mathrm{B}}$-received and emited signal amplitudes accordingly, $\varphi$-phase shift between amplitudes $U_{\Pi}$ and $\mathrm{U}_{\mathrm{B}}$.

So, defected joint can be located using changing mechanical impedance $|\mathrm{Z}|$ (its amplitude $\mathrm{P}$ or phase shift $\varphi$ ).

There could be some simplifications in the description of mechanical impedance of honeycomb

Corresponding Author: Dr. Monther Moh'd Krishan, The Dean of Ma'an University College, Al-Balqa Applied University, P.O. Box: 194 Ma'an, Jordan 71111 
structure. For instance, the part of skin with defect is considered as a plate fixed around a defect contour. Then a size of a defect is defined by a size of this plate. Input impedance of a such plate can be expressed ${ }^{[3]}$ :

$$
\mathrm{Z}_{1}=\mathrm{j}\left[\omega \mathrm{m}-\frac{1}{\omega \mathrm{K}_{1}}\right]
$$

Where:

$\mathrm{Z}_{1}=$ Mechanical impedance of a defected part

$\mathrm{m}=$ Physical mass of a plate with diameter $\mathrm{D}$

$\mathrm{K}_{1}=$ Slenderness ratio of a plate in the center and

$\omega=$ Angular frequency

Input impedance of flaw-free honeycomb part is defined as ${ }^{[4]}$ :

$$
Z_{2}=\frac{j X}{1-X \omega \frac{l_{k}}{D_{k}}}
$$

Where:

$\mathrm{Z}_{2}=$ Mechanical impedance of a flaw-free part

$\mathrm{X}=$ Mechanical impedance of the honeycomb cell edge $X=\rho_{\mathrm{s}} 1_{\mathrm{s}}$ where

$\rho_{\mathrm{s}}, 1_{\mathrm{s}}=$ Are the density and thickness of a honeycomb cell plate respectively

$1_{\mathrm{k}}=$ Thickness of glue

$D_{k}=$ Constant dependent on glue physical characteristics

The purpose of this research is to investigate the influence of acoustical channel components on the result of honeycomb structure testing with impedance method. It is necessary to provide mathematical simulation of the impedance method testing of honeycomb structure and analyze the influence of testing object parameters on the result of testing.

\section{SIMULATION OF MECHANICAL IMPEDANCE OF A DEFECTED STRUCTURE}

Let's consider mechanical impedance of multilayer structure in a defected part. Assume that a defect has a circle configuration with a diameter D. Reactive part of mechanical impedance $\mathrm{X}$ of a plate, then it is possible to express, using equivalent the mass and slenderness ratio of a plate $K_{e}$, which is excited in the center by concentrated force ${ }^{[5]}$ :

$$
\mathrm{m}_{\mathrm{e}}=\frac{7}{256} \rho \pi \mathrm{hD}
$$

$$
K_{e}=3 \frac{\left(1-\mu^{2}\right) D^{2}}{16 \pi \mathrm{Eh}^{3}}
$$

where, $\rho, \mathrm{h}, \mathrm{E}$ are density, thickness and Young's modulus of the plate. Then:

$$
\mathrm{Z}_{1}=\mathrm{X}=\mathrm{j}\left[\omega \mathrm{m}_{\mathrm{e}}-\frac{1}{\omega \mathrm{K}_{\mathrm{e}}}\right]
$$

Defect is considered as a filled up gas layer. Thickness of this layer is greatly less then wave-length in the gas. Than, concentrated slenderness ratio of such layer is:

$$
\mathrm{K}_{\Gamma}=\frac{64 \mathrm{~h}_{\Gamma}}{\rho_{\Gamma} \mathrm{c}_{\Gamma}^{2}(\pi \mathrm{D})^{2}}
$$

Where:

$\mathrm{h}_{\Gamma}$ : The average thickness of a gap

$\rho_{\Gamma}$ : Gas density and

$\mathrm{c}_{\Gamma}$ : Sound velocity in gas

Total slenderness ratio will be defined by following expression:

$$
\mathrm{K}_{\mathrm{e}}^{\prime}=\frac{\mathrm{K}_{\mathrm{e}} \mathrm{K}_{\Gamma}}{\mathrm{K}_{\mathrm{e}}+\mathrm{K}_{\Gamma}}
$$

Let's determine the influence of the defect opening on mechanical impedance. For that, it is necessary to calculate correlation between concentrated slenderness ratio without taking into account a defect $\mathrm{K}_{\mathrm{e}}$ and with total slenderness ratio $\mathrm{K}_{\mathrm{e}}^{\prime}$ :

$$
\frac{\mathrm{K}_{\mathrm{e}}}{\mathrm{K}_{\mathrm{e}}^{\prime}}=\frac{3\left(1+\mu^{2}\right) \mathrm{c}_{\Gamma} \rho_{\Gamma}^{2} \mathrm{D}^{4}}{1024 \cdot \mathrm{Eh}_{\Gamma} \mathrm{h}^{3}}+1
$$

Figure 1 shows the dependence $\mathrm{K}_{\mathrm{e}} / \mathrm{K}_{\mathrm{e}}^{\prime}$ on gap opening for some values of the aluminium plate diameter. It is obvious that the larger the defects will have the greatest influence on impedance. Exactly in that case defects provoke abrupt change of the signal level and they can be defined quite clear.

Let us calculate reactive component of impedance for a honeycomb structure using Eq. 7:

$$
\mathrm{X}=\omega\left(\frac{7}{256} \rho \pi \mathrm{hD^{2 }}\right)-\frac{1}{\omega \cdot 0.0597 \frac{\left(1-\mu^{2}\right) \mathrm{D}^{2}}{\mathrm{E} \cdot \mathrm{h}^{3}}}
$$

Figure 2 shows the results of mathematical simulation of mechanical impedance for an object at different frequencies and different defect diameters. 


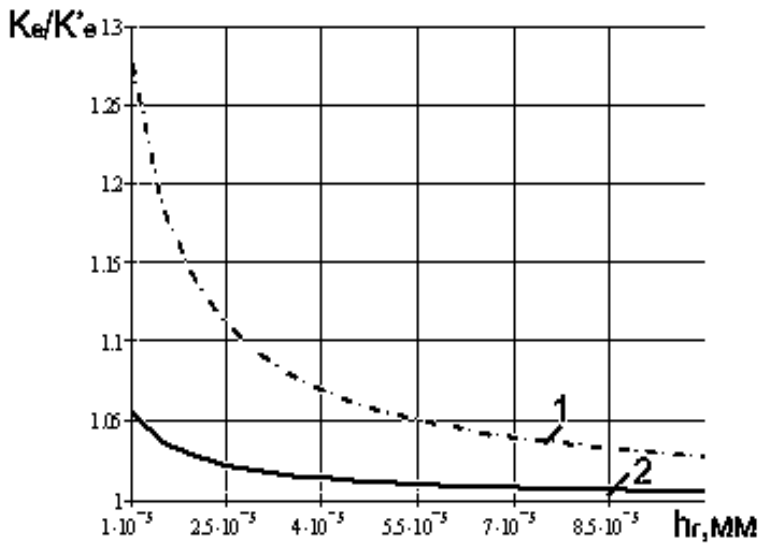

Fig. 1: Dependence $\mathrm{K}_{\mathrm{e}} / \mathrm{K}_{\mathrm{e}}^{\prime}$ on Gap Opening $\mathrm{h}_{\Gamma}$ adjoint air layer. 1-D $=32 \mathrm{~mm}$; 2-D $=24 \mathrm{~mm}$

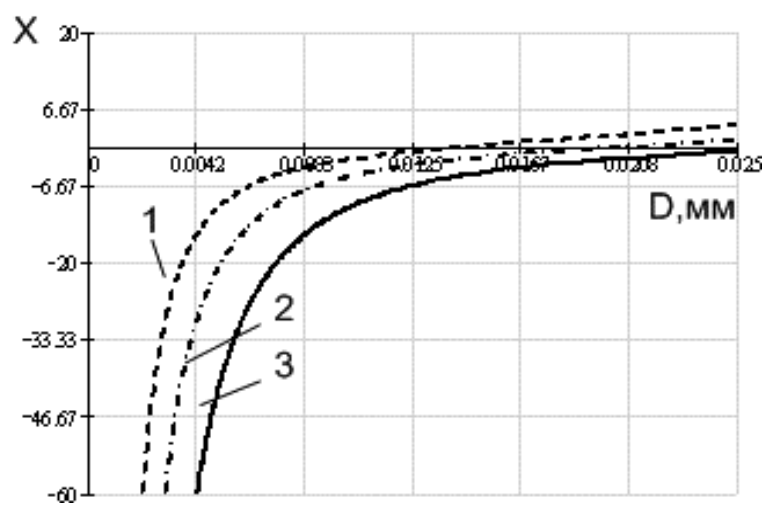

Fig. 2: Calculation results of object mechanical impedance at different frequencies and defect diameters. 1 - doubled frequency $2 \omega$; 2 -working frequency $\omega ; 3$-half of working frequency $\omega / 2$

\section{SIMULATION OF ACOUSTICAL CHANNEL}

So, when frequency grows, the module of reactive component of impedance grows also. As well as we can see some non-perfection of a chosen model, i.e., when defect is absent $(D=0)$, the value of impedance mustbe finite.

Let us consider the dependence of the acoustical sensor transfer factor $\mathrm{P}=\mathrm{U}_{\Pi} / \mathrm{U}_{\mathrm{B}}$ on mechanical impedance of an object $Z$. This factor is the characteristic of an acoustical channel. The main result of acoustical channel calculation is attenuation factor of an acoustical channel or simply factor of an acoustical channel. This factor depend on ratio between mechanical impedance of defected and flaw-free parts of a honeycomb structure.



Fig. 3: Influence of thickness of honeycomb cells on the acoustical channel factor for different values of cylindrical rigidity of material L. $1-\mathrm{L}=0.02$; $2-\mathrm{L}=0.04 ; 3-\mathrm{L}=0.06 ; 4-\mathrm{L}=0.08$

$$
\mathrm{K}_{\text {A.T. }}=\frac{\mathrm{Z}_{1}}{\mathrm{Z}_{2}}
$$

It is necessary to find the ratio between Eq. 3 and 4:

$$
\mathrm{K}_{\text {A.T. }}=\frac{\frac{7}{256} \rho \pi \mathrm{hD}^{2} \omega-\frac{16 \pi \mathrm{Eh}^{3}}{3\left(1-\mu^{2}\right) \mathrm{D}^{2} \omega}}{\frac{\omega \rho_{\mathrm{s}} 1_{\mathrm{s}}}{1-\omega^{2} \rho_{\mathrm{s}} 1_{\mathrm{s}} \frac{1_{\mathrm{s}}}{D_{\mathrm{k}}}}}
$$

Subject to some simplification and change, the equation for an acoustical channel factor for impedance method testing becomes:

$$
\mathrm{K}_{\text {A.T. }}=\left(0.13 \mathrm{~m}-\frac{64 \pi \mathrm{L}}{\mathrm{D}^{2} \omega^{2}}\right) \cdot\left(\frac{1}{\rho_{\mathrm{s}} 1_{\mathrm{s}}}-\omega^{2} \frac{1_{\mathrm{k}}}{\mathrm{D}_{\mathrm{k}}}\right)
$$

where, $\mathrm{L}$ is the cylindrical rigidity of material.

It can be seen that the physical and mechanical properties of testing object have influence on the acoustical channel factor. From Fig. 3 shows us that, when density and thickness of honeycomb cells go up, the cylindrical rigidity of material goes and a defect can be found easily.

\section{AMPLITUDE METHOD OF TESTING}

The object impedance $\mathrm{Z}$ is defined using sensor output signal at the amplitude method. For honeycomb panels with periodic structure we have periodic change of a signal for flaw-free parts. The value of voltage is minimal for the areas with the most separation from 
skin-cell joint and maximal above it. So,for a honeycomb panel the minimals correspond to the centers of honeycomb cells and maximals correspond to the tops of honeycomb cells. That is why, indication value of a detector for flaw-free periodic structure part will be quite different.

Figure 4 shows honeycomb cells location under the skin. At the bottom of the figure there is a plot of detector indication changes at the movement of an integrated sensor. The path of a sensor is shown by a dashed line. If a defect alarm appears at the level below $\mathrm{I}$, only defect area is recorded.

At the level II the honeycomb cells are recorded as defects. Spread in values for flaw-free parts is more when slenderness ratio of a skin is less and cell size is large.

Using Eq. 15, let us calculate the voltage amplitude for sensor location: In flaw-free area and above the center of a cell for the cases of minimal and maximal defect.

$$
\mathrm{U}=\mathrm{U}_{3 \sigma} \cdot \mathrm{T} \cdot \mathrm{K}_{\text {E.A.T. }}
$$

Where:

$\mathrm{U}_{36} \quad=$ Voltage applied to a radiated component

$\mathrm{T}=$ Transmitted factor for aacoustical signal run over the layers of honeycomb structure and

$\mathrm{K}_{\text {E.A.T }}=$ Electro-acoustical channel factor

Below are the calculated amplitude values for detector output signals:

- For flaw-free junction amplitude values of output signals are within $6.4 \mathrm{mV}$ and 5.08 V. On Fig. 4, it corresponds to the volage range [U2min; U2max]

- For defect junction (minimal defect is $0.016 \mathrm{~m}$ ) amplitude values for detector output signals will be less then $3.3 \mathrm{mV}$. On Fig. 4, it corresponds to a mark I

\section{PHASE METHOD OF TESTING}

As was mentioned previously, defect joint can be disclosed using not only amplitude signal changing but phase shift as well (1).

Active component of the impedance can be written $^{[5]}$ :

$$
\mathrm{Z}=2.31 \mathrm{~h}^{2} \sqrt{\frac{\mathrm{E} \rho}{1-\mu^{2}}}
$$

Reactive component of the impedance can be calculated using Eq. 11 .

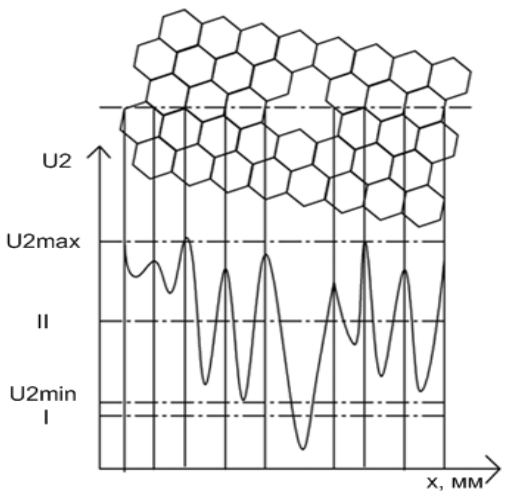

Fig. 4: Measurement of a signal amplitude at the output of an integrated sensor for honeycomb panel testing by impedance method

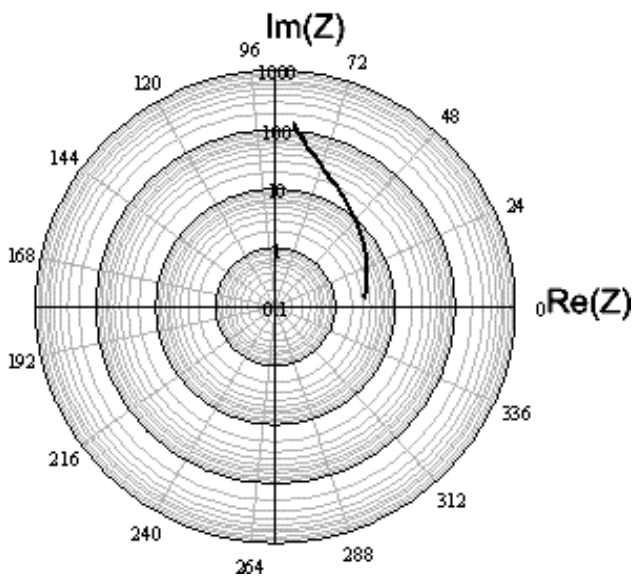

Fig. 5: Graph of impedance complex value

Let us difine the defect size from $0.016 \mathrm{~m}$ to $0.1 \mathrm{~m}$ and apply Eq. 1, 11 and 16. After that, the graph of impedance complex value can be found.

As illustrated in Fig. 5, that the phase component change very little in the range of defects. It is clear that with a low value of mechanical impedance for a considered honeycomb structure, the amplitude mode is more informative for honeycomb panels testing.

\section{CONCLUSION}

The mathematical model of mechanical impedance for honeycomb structure has been presented in this research. This model can be used to analyze influence defects feature, object parameters and condition of excitation on results of impedance method testing.

The simulated results demonstrate how defect size and material of a cell and skin influence on mechanical impedance of structure. 
Also, the research outlines the amplitude and phase mode of the impedance method. It was shown that amplitude mode is more informative at honeycomb panels testing.

\section{REFERENCES}

1. Barnard, D.J. and D.K. Hsu, 2005. Development of practical NDE methods for composite aircraft structure. Rev. Prog. QNDE, 25B: 1019-1026.

2. Неразрушающий контроль металлов и изделий. Справочник. Под ред. Г.С. Самойловича. М., «Машиностроение», 1976-456с. С ил.
3. Ланге Ю.В. Акустические низкочастотные методы и средства неразрушающего контроля многослойных конструкций. - М.: Наука, 1991. $272 \mathrm{c}$.

4. Ланге Ю.В. О физических основах ультразвукового метода неразрушающей оценки прочности клеевых соединений// Дефектоскопия. - 1974. - № 1. - с. 96-107.

5. Скучик Е. Простые и сложные колебательные системы. - М.: Мир 1971. -557c. 